\title{
Reorientando a identidade nacional em Native speaker, de Chang-rae Lee, e O sol se põe em São Paulo, de Bernardo Carvalho
} Rex P. Nielson ${ }^{1}$

O cineasta brasileiro do início do século XX Alberto Cavalcanti, o qual passou a maior parte de sua carreira na Europa trabalhando na vanguarda do cinema francês e britânico, inicia o seu filme de 1926 Rien que les heures com a seguinte provocação: "Todas as cidades pareceriam a mesma se não fossem os monumentos que as diferem". ${ }^{2}$ Com Rien que les heures Cavalcanti uniu-se a uma longa tradição do realismo documental urbano enfocando os desafios comuns da vida na cidade. É uma premissa defendida frequentemente por artistas, ${ }^{3}$ escritores $^{4}$ e cineastas: ${ }^{5}$ as vicissitudes da metrópole unem as pessoas que habitam locais tão díspares como Tóquio, Paris, Nova York e São Paulo. No entanto, mesmo que artistas contemporâneos celebrem ou critiquem a experiência compartilhada da vida metropolitana em todo o mundo, as cidades também servem como símbolos únicos para suas respectivas culturas e nações. Apesar da afirmação de Cavalcanti ao contrário, cidades - sobretudo as grandes cidades - revelam exclusivos contornos da identidade cultural e nacional. No Brasil e nos Estados Unidos, as cidades de São Paulo (SP) e Nova York (NYC), dois dos grandes centros de imigrantes das Américas, há muito tempo manifestam uma ansiedade a respeito dos princípios da inclusão e do pertencer, da assimilação e da autenticidade particular de cada nação. Em grande medida, as populações imigrantes definiram as duas cidades em termos de arquitetura e planejamento urbano, dando simultaneamente nova

\footnotetext{
${ }^{1}$ Doutor em estudos portugueses e brasileiros na Brigham Young University, Provo, UT, Estados Unidos. E-mail: rex_nielson@byu.edu

${ }^{2}$ Para mais informações sobre Alberto Cavalcanti, ver Fabris (2007) e Martins (2002).

3 Exemplos de fotografia incluem o trabalho do artista canadense Edward Burtynski $(<\mathrm{http} / / /$ www.edwardburtynsky.com $\rangle)$ e do artista norte-americano Daniel Everett (<http://www.daniel-everett.com>). O trabalho de ambos os artistas procura minimizar a localização dos equipamentos e as provas da vida metropolitana a fim de enfatizar a experiência comum da vida metropolitana industrializada.

${ }^{4}$ A ficção urbana de Luiz Ruffato se destaca nesse sentido.

${ }^{5}$ Exemplos incluem os documentários de Eduardo Coutinho.
} 
forma e direção para debates de longa data sobre raça, etnia e identidade nacional.

Escritos no clima de frequentes e acerbos debates públicos, tanto nos Estados Unidos quanto no Brasil, a respeito de raça e imigração, o romance Native speaker (1995), do escritor norte-americano Chang-rae Lee, e $O$ sol se põe em São Paulo (2007), de Bernardo Carvalho, ponderam os papéis dos imigrantes asiáticos nos Estados Unidos e no Brasil, e uma análise comparativa dos dois romances elucida a política racial em jogo em ambos os países. Os dois romances são estruturados de modos muito semelhantes e são centrados na metrópole de seus respectivos países. Native speaker detalha a experiência de um narrador da segunda geração coreana-americana em Nova York. O sol se põe em São Paulo, por outro lado, começa e termina em São Paulo com um narrador sansei, ou seja, neto de imigrantes japoneses. Ambos os enredos se concentram na crise de identidade de um narrador tentando negociar sua identidade americana (em termos hemisféricos) em relação à origem de sua família e ao idioma, porém também em relação ao lugar, ou seja, ambos os romances não abordam apenas a questão de ser um imigrante, mas de ser um imigrante em Nova York e em São Paulo. As duas cidades são centros históricos de imigração, onde os imigrantes impactaram significativamente a dinâmica racial nacional, onde os imigrantes construíram seu segundo lar, e, ainda por causa disso, elas também são cidades cheias de companheiros inesperados, cruzamentos incomuns, o entre-lugar no meio de espaços que não são inteiramente nem aqui nem lá. Consequentemente, enquanto ambas Nova York e São Paulo simbolizam o espaço nacional, simultaneamente abrigam elementos culturais alienígenas e estrangeiros que desafiam e subvertem a identidade nacional.

Tanto Native speaker quanto $O$ sol se põe em São Paulo conceituam a ansiedade a respeito de raça e identidade nacional em função da metrópole. Ambos os romances revelam as configurações idiossincráticas e até mesmo orgânicas de NYC e SP que deram lugar aos imigrantes, minorias, entre outros grupos étnicos. Enquanto políticas raciais nos Estados Unidos e no Brasil surgem tipicamente dentro de um espectro de polos entre o negro e o branco (obviamente de forma particular e exclusiva para cada país), examinar a experiência de imigrantes asiáticos nas metrópoles americanas (NYC/SP) é uma forma útil de fazer uma triangulação para pensar as dinâmicas raciais da 
identidade nacional no Brasil e nos Estados Unidos. Nesse sentido, Native speaker explora um desejo constante presente na cultura dos Estados Unidos para superar, abrandar ou eliminar o hífen de marginalização que impede alguns imigrantes de se assimilarem a um ideal "americano". Por outro lado, O sol se põe em São Paulo de Carvalho aborda o tema de forma contrária, tentando recuperar o hífen, ou seja, para preservar uma herança étnica que muitas vezes é omitida nas discussões sobre a identidade nacional do Brasil.

As relações raciais comparativas entre os Estados Unidos e o Brasil têm uma longa história de estudos diversificados, inclusive os do século XIX do abolicionista e estadista Joaquim Nabuco, os do sociólogo e antropólogo Gilberto Freyre ou ainda do estimado historiador Thomas Skidmore. Somente nos últimos dez anos tem se visto uma proliferação impressionante de estudos comparativos relacionados à raça. ${ }^{6}$ Uma breve avaliação dessa pesquisa indica consistentemente que, apesar das diferenças fundamentais na maneira pela qual a raça foi construída nos Estados Unidos e no Brasil, tais construções raciais ocorreram dentro de um espectro definido por dois polos: o negro e o branco. Na verdade, uma análise cuidadosa dessa literatura crítica sobre as relações raciais revela a conclusão surpreendente de que a identidade asiática nas Américas raramente fatora nas formas pelas quais a identidade nacional é configurada pela raça, mistura racial e etnia. Talvez não seja tão surpreendente, dada a relativamente pequena percentagem de participação detida por imigrantes asiáticos nos Estados Unidos e no Brasil entre todos os grupos raciais e étnicos. No entanto, o tamanho da população não é inteiramente um fator determinante tendo em vista o peso dado aos povos indígenas nos mitos de identidade nacional. Existem razões históricas e óbvias para isso, entretanto, a percentagem de asiáticos no Brasil é quase o triplo do tamanho da população indígena; e nos Estados Unidos é quase cinco vezes maior. Mesmo assim, as populações asiáticas permanecem constantemente ausentes em estudos comparativos sobre as relações raciais nos Estados Unidos e no Brasil.

${ }^{6}$ Considerar as seguintes publicações acadêmicas norte-americanas: Hamilton et al. (2001), Stam (1997), Daniel (2006), Telles (2004), Seigel (2009), Marx (1998) e Persons (2003). Ou estas, brasileiras: Fausto (1999), Souza (1997), Lessa (2008), Azevedo (2003). Esses são apenas títulos da última década. Estudos clássicos do assunto como Black into White: race and nationality in Brazilian thought, de Skidmore (1993 [1974]) continuam a ser um ponto de referência para estudos comparativos. 
No entanto, já que as populações asiáticas frequentemente recebem consideração fora do eixo negro/branco que define a raça, principalmente no Brasil e nos Estados Unidos, uma análise comparativa de Native speaker e $O$ sol se põe em São Paulo ilumina o nosso entendimento a respeito da questão da raça, destacando a dinâmica racial dos dois países de uma forma reconhecidamente atípica (minoria), porém, reveladora. Native speaker e $O$ sol se põe em São Paulo compartilham angústias semelhantes a respeito de assimilação, que em sua essência é uma ansiedade sobre a autenticidade. O que significa ser autenticamente brasileiro? $\mathrm{O}$ que significa ser autenticamente americano? A identidade nacional depende, naturalmente, da redução e generalização, apesar do fato de que "nenhum traço caracteriza uma nação inteira, a não ser a própria nação, e nenhum quadro ideológico único pertence uniformemente por todo um espaço nacional" (Seigel, 2009 , p. 2), no entanto, esses romances revelam diferenças cruciais nas formas como os Estados Unidos e o Brasil responderam à alteridade cultural. Este é, afinal, o poder da ficção. A ficção serve tanto para agregar e fundir noções de raça, etnia e nacionalidade, quanto para separar e expor as diversas vertentes do tecido nacional, e Native speaker e $O$ sol se põe em São Paulo apresentam uma autoconsciência aguda do poder da ficção para fazer isso, mesmo quando em última análise desafiam mitos nacionais de inclusão e aceitação.

Diferenças chaves distinguem as tradições culturais do Brasil e dos Estados Unidos que são a base de Native speaker e $O$ sol se põe em São Paulo. Análises comparativas sempre correm o risco de banalização, e, ainda que eu faça uso de linhas gerais para caracterizar as diferenças entre ambos os países, minha intenção não é oferecer um quadro paradigmático para a compreensão de raça, etnia e identidade nacional, mas, sim, um quadro provisório que possa ser útil para a compreensão desses dois romances. Nos Estados Unidos, a noção de melting pot ["caldeirão cultural"] continua a ser um ponto de referência significativo em debates sobre a imigração, etnia, raça e assimilação. Em reação às tendências xenófobas ou nativistas, o termo ganhou espaço na primeira década do século XX como uma metáfora entusiasmada de assimilação. ${ }^{7}$ Essa ideia se encaixa no sonho

\footnotetext{
${ }^{7} \mathrm{O}$ termo foi cunhado e popularizado por uma peça intitulada The melting pot, de Israel Zangwill, que excursionou por todo os Estados Unidos em 1908 e 1909 (Zangwill, 1909).
} 
democrático americano, segundo o qual, independentemente de classe social, origem, língua, raça ou etnia, os imigrantes poderiam ganhar inclusão nos Estados Unidos. Essa aspiração até mesmo encontra expressão no lema dos Estados Unidos: e pluribus unum [de muitos, um]. Ao longo da história do país, tanto estadistas quanto escritores exaltaram esse princípio. Por exemplo: em seu prefácio ao famoso Leaves of grass (1855), Walt Whitman chamou os Estados Unidos de "uma nação repleta de nações", uma frase mais tarde celebrada pelo escritor Louis Adamic na década de 1930 e depois pelo presidente John F. Kennedy nos anos 1960 (Chametzky, 1989, p. 5).

Mesmo assim, o melting pot nunca foi a metáfora verdadeira para descrever as dinâmicas de raça e etnia nos Estados Unidos. Jules Chametzky observa que, no início dos anos 1960, estudos acadêmicos "mostraram como os grupos étnicos persistiam em manter a sua identidade, apesar das inúmeras previsões de seu desaparecimento inevitável ou diminuição sob o impacto de nivelamento de forças americanizadoras como: escolas públicas, local de trabalho, meios de comunicação" (1989, p. 3). ${ }^{8}$ Como um crítico declarou sem rodeios: "o 'melting pot' simplesmente não aconteceu" (apud Chametzky, 1989, p. 3). Assim, os teóricos culturais propuseram uma variedade de outros termos para substituir o melting pot - termos que mais bem expressam o pluralismo cultural da sociedade americana: patchwork quilt ["manta de retalhos"], gorgeous mosaic ["belo mosaico"], stew ["ensopado"], tossed salad ["salada mista"].

Talvez não seja coincidência que quase no mesmo momento histórico em que a noção do melting pot começou a fazer parte do discurso público nos Estados Unidos, W. E. B. Du Bois publicou sua coleção de ensaios The souls of black folk (1903, p. 19) no qual observou de forma legitimamente notável que "o problema do século XX é o problema da linha de cor". Em contraste marcante com a metáfora esperançosa do melting pot, a ideia de uma linha de cor, uma barreira de separação entre as raças, entre as construções da negritude e da brancura dos Estados Unidos, foi manifestada de inúmeras formas ao longo do século passado através das leis de Jim Crow e proibições contra a miscigenação, e até leis mais recentes sobre a língua oficial do país. Essas diversas medidas

${ }^{8}$ Ver, por exemplo, Glazer e Moynihan (1963), Gordon (1964) e Gleason (1964). 
legais efetivamente reinscreveram não apenas as divisões raciais mas também as diferenças étnicas.

$\mathrm{Du}$ Bois argumentou que na sociedade norte-americana a linha de cor criou uma dupla consciência no que diz respeito a assuntos de minorias raciais ou étnicas:

É uma sensação estranha sempre olhar para si mesmo através dos olhos dos outros, medir a nossa alma pela fita métrica de um mundo que nos observa com desprezo trocista e piedade. Sente-se sempre esta dualidade - um americano, um negro; duas almas, dois pensamentos, dois anseios irreconciliáveis; dois ideais em contenda num corpo escuro que só não se desfaz devido à sua força tenaz (Du Bois, 1903, p. 3).

Aqui $\mathrm{Du}$ Bois lamenta as tensões psicológicas decorrentes da privilegiada brancura perante a alteridade marginalizada, um argumento mais tarde desenvolvido por outros intelectuais anticoloniais, como Frantz Fanon e Amílcar Cabral. ${ }^{9}$

Apesar de Du Bois examinar a linha de cor e sua consequente dupla consciência em referência específica a tensões raciais entre brancura e negritude nos Estados Unidos, esses conceitos sugerem implicações significativas quanto à forma pelas quais as outras etnias são vistas e recebidas na cultura americana. Em oposição ao termo melting pot, todas as metáforas posteriores como patchwork quilt, gorgeous mosaic, stew e tossed salad essencialmente preservam, para melhor ou pior, uma linha divisória baseada em cor, e vários estudos demonstram como as minorias raciais e étnicas negociam a dupla consciência induzida pela linha de cor. ${ }^{10}$

Uma maneira como os Estados Unidos responderam ao pluralismo cultural e ao desejo de reconhecer a diferença está presente no hífen aparentemente benigno que permeia a nomenclatura da sociedade norteamericana hoje em dia: Italian-American, Irish-American, Hispanic-American, Chinese-American e Korean-American (como no caso de Native speaker). O lado oculto da retórica inclusiva dos Estados Unidos, uma autoafirmação do país como uma nação de nações, é que a sociedade americana sempre se

\footnotetext{
${ }^{9}$ Para um excelente estudo comparativo de Du Bois, Fanon e Cabral, ver Peterson (2007) e Keller e Fontenot (2007).

10 Ulf Hannerz (1992, p. 132) comenta, por exemplo: "Membros de minorias étnicas frequentemente afirmam sentir uma 'dupla consciência', resultado de tensões de perspectivas vindas de dentro seu próprio grupo e daquelas que são prevalentes na sociedade em geral”. Ver também Fong e Chuang (2004).
} 
sentiu pouco à vontade com seus imigrantes. Enquanto para alguns o hífen pode parecer uma hipercorreção contra um discurso prévio de eugenia, uma ponte politicamente correta que recupera, respeita e reconhece a diversidade étnica e cultural dos Estados Unidos, a partir de uma perspectiva diferente, o hífen é apenas a manifestação mais recente para reforçar a linha de cor, uma forma de manter os outros grupos étnicos e raciais a distância. Jules Chametzky ressalta essa tensão quando observa que: "o reconhecimento de diversidade étnica na América, que antes era uma celebração geral da riqueza da mistura, agora estremece ante o espectro das diferenças divisivas e irreconciliáveis" (1989, p. 4). É claro que muitos grupos de minorias étnicas e raciais abraçaram o hífen como uma forma de preservar as diferenças culturais. No entanto, se visto de forma positiva ou negativa, e se apropriado conscientemente ou não, o hífen reforça modos dominantes de identidade ao mesmo tempo que sinaliza a diferença racial, étnica e cultural. Em suma: o hífen é o gueto em sintaxe.

Durante o século XIX e XX, os imigrantes irlandeses e italianos encontraram-se no lado escuro de uma noção culturalmente construída a respeito do que quer dizer ser branco, um discurso eugenista no qual não foram considerados como brancos, sendo impulsionados para o outro lado da linha de cor e identificados mais com afro-americanos do que brancos europeus do norte. Considere, por exemplo, a maneira pela qual os imigrantes irlandeses eram consistentemente identificados como uma raça swarthy [escura]. Na verdade, inúmeras caricaturas irlandeses de 1890 mostraram frequentemente imigrantes irlandeses como swarthy apes [macacos escuros], assim identificando-os como um grupo étnico e racial que era decididamente negro. Da mesma forma, na década de 1920, grupos numerosos de imigrantes italianos entraram nos Estados Unidos através de Nova Orleans e em seguida trabalharam nos campos de cana-de-açúcar. Muitos desses imigrantes logo partiram em busca de novas oportunidades no oeste dos Estados Unidos devido ao aumento da violência e linchamentos indiscriminadamente feitos por sulistas brancos contra os imigrantes italianos e afro-americanos. Não é de se admirar que as diversas ondas de chineses, japoneses, coreanos e imigrantes do sudeste asiático que vieram para os Estados Unidos durante os séculos XIX e XX também se encontravam no outro lado da linha de cor - separados em termos de não serem considerados branco, como uma outra raça de cor que ameaçava a construção dominante da cor branca e dando origem ao "perigo amarelo" do século XX. De fato, 
como Chametzky observa: "o confinamento e opressão de asiáticos são marcas decisivas de nossa história" (1989, p. 12, grifo do original). Embora o número de imigrantes asiáticos constitua uma percentagem relativamente pequena da população total dos Estados Unidos, a sua presença e história iluminam os debates nacionais sobre o pluralismo cultural e as relações raciais.

A dinâmica racial no Brasil não é menos complexa e, assim como a dos Estados Unidos, é baseada em noções construídas de brancura. Embora a noção do melting pot continue a manter sua presença no discurso racial nos Estados Unidos, mesmo sendo inadequada como metáfora, o termo mestiçagem sempre esteve no coração da configuração racial do Brasil. Mestiçagem e hibridismo, como Silviano Santiago (2011) constantemente nos lembra, são critérios destacados da teoria cultural brasileira. Ao passo que, nos Estados Unidos, houve uma preferência pelo modelo dos peregrinos e índios que compartilharam uma refeição e depois voltaram para suas casas, ${ }^{11}$ o Brasil optou pelo mito das três raças e o casamento inter-racial como uma metáfora definitiva para a nação: Iracema, de José de Alencar, A escrava Isaura, de Bernardo Guimarães, e $O$ mulato, de Aluísio de Azevedo, são romances fundamentais do século XIX baseados nos significados e possibilidades do casamento inter-racial. No entanto, dentro dessa configuração híbrida, as elites intelectuais brasileiras privilegiaram a sua própria concepção de brancura.

Uma obra recente que, de maneira astuta, reconsidera a mudança na noção de raça no Brasil é o volume coordenado por Cristina FerreiraPinto Bailey e Regina Zilberman (2010), intitulado Brasil, Brasis ou: a hora e a vez das minorias étnicas. Na introdução, Bailey e Zilberman observam um impulso poderoso dentro da literatura brasileira para promover a unidade nacional. Especialmente tendo em conta as profundas divisões políticas presentes no país na época da fundação da

\footnotetext{
${ }^{11}$ A mitologia dos Estados Unidos inclui casos de miscigenação e relacionamentos de misturas de raças, como no célebre encontro entre o colonizador John Smith e Pocahontas, a heroína indígena que salva Smith. No entanto, esse encontro tem sido apontado de forma consistente como uma exceção à regra das relações entre colonizadores e índios no contexto norte-americano. Como afirma Andrea Tinnemeyer: "Nas narrativas de cativeiro a service do colonialismo, o resgate de Smith por Pocahontas ressoa com a erótica da expansão e o cumprimento da providência divina. [No entanto] $\mathrm{O}$ excepcionalismo de Pocahontas remove simultaneamente a ameaça de miscigenação, mantendo a sua 'indianidade' para implantação quando for politicamente conveniente" (2006, p. 20).
} 
República em 1889 e as intimidações de vários estados que ameaçavam uma secessão, as elites brasileiras adotaram uma noção unificada de raça e identidade nacional. Bailey e Zilberman afirmam: “Tornou-se imprescindível adotar sistema político que representasse efetivamente a totalidade da população residente no Brasil" (2010, p. 13). No entanto, mesmo que intelectuais públicos promovessem uma imagem unificada da nação, essa imagem dependia, em grande parte, de uma construção particular de brancura e a exclusão de vários segmentos marginalizados da população. As autoras continuam: "O princípio da unidade nacional repercutia na literatura, garantida, já se vê, por muitas exclusões históricas, a começar pela exclusão de diferentes raças que participaram da edificação da sociedade brasileira" (2010, p. 13). Essas várias formas de exclusão foram sistematicamente dirigidas contra as minorias raciais e étnicas, resultado de um básico privilegiamento da brancura.

Em seu respeitado estudo Black into white, o historiador Thomas Skidmore observa que, no início do século $X X$, as elites brasileiras tentaram projetar uma imagem nacional de brancura "com o propósito de impressionar europeus e norte-americanos" (1993 [1974], p. 124). Ele observa ainda que a política de imigração favorecia deliberadamente uma propaganda de branqueamento e o governo foi orquestrado para atrair os brancos europeus, sobretudo italianos, portugueses espanhóis e alemães (1993, p. 136-144). De fato, tão poderoso era o desejo de embranquecimento, sobretudo nas regiões economicamente mais desenvolvidas do sul do Brasil, que em vez de "procurarem mão de obra livre de migrantes de outras regiões do país [...] os produtores de café tentaram substituir seus escravos depois de 1870 por imigrantes europeus" (Skidmore, 1993 [1974], p. 138). A política federal de imigração até mesmo providenciava incentivos fiscais aos donos de terras que iriam receber os imigrantes europeus em suas propriedades (Skidmore, 1993 [1974], p. 137). Assim, ao contrário dos Estados Unidos, onde os imigrantes irlandeses e italianos eram vistos de forma negativa e até mesmo taxados como negros, no Brasil, durante a mesma época, os italianos e outros imigrantes da Europa Ocidental foram bem recebidos, precisamente por causa de sua raça, vista como uma contribuição positiva para o Brasil e a sua noção de embranquecimento culturalmente criada.

Nem todos os imigrantes que foram para o Brasil vieram da Europa. No entanto, Jeffrey Lesser argumenta que durante o século XX quase 
meio milhão de asiáticos, árabes e judeus que não eram "considerados nem brancos, nem negros, foram os que mais desafiaram as noções de identidade nacional da elite" (1999, p. 7). Considere, por exemplo, as formas pelas quais a chegada de imigrantes japoneses para o Brasil foi teorizada. Inicialmente, uma expressiva minoria entre as elites brasileiras se opôs à imigração japonesa em massa. Por exemplo, o Dr. Arthur Neiva argumentou que os imigrantes japoneses eram inassimiláveis (Lesser, 1999, p. 93). O Deputado Federal Fidelis Reis também protestou contra a imigração japonesa afirmando, "o cisto amarelo permanecerá no organismo nacional, inassimilável pelo sangue, pela linguagem, pelos costumes, pela religião" (Lesser, 1999, p. 100). No entanto, essas vozes eram uma minoria clara. Sílvio Romero argumentou que "os japoneses eram exclusivamente assimiláveis devido às altas taxas casamento inter-raciais" (Lesser, 1999, p. 104). De fato, muitos grupos de elite argumentaram que um influxo de imigrantes japoneses contribuiria significativamente para o modelo de uma nação mestiça, ajudando a "embranquecer" a população ainda mais. Outros apelaram para a ciência de eugenia a fim de argumentar que os índios brasileiros e imigrantes japoneses "eram do mesmo material biológico" (1999, p. 104). Lesser observa que, se essa afirmação fosse verdadeira, então a assimilação seria fácil: "Ao sugerir que os japoneses eram brasileiros, e vice-versa, aqueles a favor da imigração japonesa conseguiram utilizar a teoria eugênica de forma irônica" (1999, p. 105). Segundo essa lógica criativa, os asiáticos eram vistos como os progenitores de quem residia na Amazônia, tornando-os mais autenticamente brasileiros do que a maioria dos próprios brasileiros.

Assim sendo, através de um processo complexo e negociado, os nipo-brasileiros foram incorporados à imagem miscigenada da identidade nacional do Brasil. O forte anseio do Brasil por uma unidade cultural e nacional rendeu uma dupla consequência: considerável esforço intelectual foi dedicado para facilitar a assimilação das minorias étnicas e raciais; todavia, ao mesmo tempo, a diversidade cultural significativa foi escondida quando tal diferença não era facilmente assimilada, e a nação, por sua vez, com frequência, não levou em consideração as minorias étnicas por não serem consideradas suficientemente brasileiras. Apenas nas últimas décadas foi feito um trabalho significativo para recuperar os outros grupos escondidos e oprimidos pela hegemonia cultural do Brasil. Como Bailey e Zilberman 
(2010) demonstram, o reconhecimento da alteridade desenvolveu-se lentamente no Brasil durante o século XX. No final do século, os estudos literários, a história, a etnografia, a antropologia e a sociologia mais do que nunca começaram a explorar a presença rica, diversificada e complexa dos africanos, portugueses, espanhóis, alemães, italianos, japoneses, judeus e árabes no Brasil. Semelhante ao gorgeous mosaic dos Estados Unidos, muitos acadêmicos das ciências sociais até mesmo já adotaram o termo "mosaico étnico" para descrever o pluralismo cultural presente na cultura brasileira.

Assim, enquanto ambos Native speaker e $O$ sol se põe em São Paulo ponderam as políticas de identidade de sujeitos que estão lutando para negociar a sua identidade "americana" vis-à-vis sua herança étnica asiática, eles o fazem em contextos radicalmente diferentes. O narradorprotagonista de ambos os romances se sente alienado por causa do componente asiático de sua identidade; no entanto, esses sentimentos de alienação são o resultado de forças culturais que se diferem. No caso de Native speaker de Lee, a linha de cor - graficamente manifestada no hífen usado pelo narrador coreano-americano - estabelece uma linha de base para o desejo do protagonista pela assimilação cultural. Por outro lado, em $O$ sol se põe em São Paulo, o narrador se sente sobrecarregado por uma herança cultural que a vasta sociedade consistentemente se recusa a reconhecer.

\section{Native speaker e a inquietação dos Estados Unidos a respeito da identidade hifenizada}

O primeiro romance de Chang-rae Lee, Native speaker (1995), demonstra que a inquietação sobre assimilação permanece viva e ativa nos Estados Unidos. Lee, filho de imigrantes coreano-americanos, cresceu em New Rochelle, em Nova York, na década de 1970, onde “a maioria das empresas locais era administrada pelos descendentes de imigrantes que, algumas gerações antes, tinham vindo de Nova York para os subúrbios. Bem marcados na Main Street e na North Avenue estavam a padaria e a queijaria italianas, alfaiates e lavanderias judeus e açougueiros e padeiros poloneses e alemães" (Lee, 2003, p. 104). ${ }^{12}$ Lee

\footnotetext{
${ }^{12}$ Lee nasceu na Coreia em 1965, mas emigrou para os Estados Unidos com seus pais quando tinha três anos de idade. Ele foi criado em um subúrbio de Nova York. Formou-se na Yale University e depois recebeu um MFA, um título de mestre em artes plásticas e literatura criativa, da
} 
baseia-se nessa diversidade étnica em sua escrita ao abordar temas sobre família, linguagem, identidade, casamento e assimilação. Seu trabalho frequentemente explora as dificuldades encontradas pelos imigrantes e seus filhos, que se sentem incapazes de assimilar ou que lutam para navegar na cultura de sua terra adotiva. Ainda que os protagonistas de seus romances e histórias nem sempre são imigrantes ou membros de grupos étnicos minoritários, eles quase sempre pessoas são que se sentem alienadas na sociedade ou que sofrem com alguma forma de dissonância cultural.

Native speaker é centrado na vida de Henry Park, filho de imigrantes coreanos. Bem-educado e profissionalmente bem-sucedido, Henry, para todos os efeitos, alcançou o sonho que trouxe seus pais para a América e parece ter assimilado a cultura americana perfeitamente. Apesar de tantas vezes estarem presentes entre as comunidades de minorias étnicas, as aparências podem enganar, e Henry é um indivíduo que se sente pouco à vontade consigo mesmo e com a sociedade. Profissionalmente, Henry segue o plano de carreira pouco comum de espionagem corporativa. Ele trabalha para uma empresa de Nova York, Glimmer e Co., especializada em ethnic coverage ["cobertura étnica"], contratando imigrantes de primeira geração para observar e informar sobre as comunidades de imigrantes das quais fazem parte (Cooper, 1995, p. 1). Henry, por exemplo, é contratado como um "agente étnico" para se infiltrar na campanha política de John Kwang, um vereador coreano-americano do bairro Queens que está virando um político proeminente em sua campanha para prefeito.

No entanto, apesar da profissão de Henry, Native speaker não é um thriller de espionagem, pelo menos não no sentido tradicional. Talvez um termo mais preciso para a profissão de Henry seja espionagem cultural. Como Henry afirma no final do romance: "Para ser um verdadeiro espião de identidade, você deve ser um espião da cultura" (Lee, 1995, p. 206). À medida que Henry se aproxima de seu alvo, Kwang, ele reflete ao mesmo tempo sobre a dinâmica cultural de Nova York e sua complexa história e identidade - é como se ele estivesse espionando a si mesmo. Através desses momentos de reflexão, descobrimos que Henry (como qualquer sujeito) é mais complexo do

Universidade de Oregon. Seu primeiro romance, Native speaker (1995), ganhou o prestigiado prêmio PEN/Hemingway. Ele ensina escrita na Universidade de Princeton e atualmente trabalha como diretor do Programa de Criação Literária de Princeton. 
que uma caricatura. Henry não é apenas coreano-americano filho de imigrantes. Também é um marido, e seu casamento está em crise em parte porque ele é um espião, uma profissão que, por vezes, torna-o frio e distante de sua esposa branca, Lelia, que não é coreano-americana e não consegue entender a dinâmica da família de Henry. O relacionamento do casal se encontra também ameaçado pela morte acidental de seu único filho, Mitt, cuja morte ocorreu anos antes, mas continua a ser uma fonte de dor não resolvida entre eles. Uma vez que a justaposição de narrativas familiares e espionagem possa parecer incomum, o romance aborda a questão da assimilação étnica tanto em termos de esfera pública quanto privada. Como Liam Corley afirma: “A interação entre a dimensão política e familiar permite ao autor criticar os paradigmas dominantes de privilegiamento racial nos Estados Unidos" (2006, p. 56). Portanto, o romance possui partes iguais: thriller de espionagem, comentário político, história de amor doméstica e memórias, com sua identidade genérica que é tão hifenizada e complexa quanto o seu narrador.

O imigrante como espião tem uma longa tradição na ficção dos Estados Unidos, e Lee inteligentemente se apropria desse conceito para problematizar a posição de Henry tanto como informante cultural e intruso. ${ }^{13}$ Ao colocar o personagem no papel de espião cultural, um papel que depende da capacidade do agente de ser invisível, Lee faz uma clara referência ao Invisible man, de Ralph Ellison (1952), um romance sobre as criações da brancura e negritude e da (in)visibilidade de um homem negro na cultura americana nos meados do século XX. No caso de Native speaker, a alienação cultural de Henry Park também resulta da construção normativa de brancura que isola asiáticosamericanos. Tina Chen argumenta: "Lee apresenta o Henry como o detetive pós-moderno cujos problemas com linguagem e performance $o$ levam a questionar os papéis designados e as formas de fala concedidas a ele" (2002, p. 638). Ao caracterizar Henry como um espião, Lee enfatiza o desempenho de Henry quanto à cultura, à brancura e ao coreanismo, como ele entra e sai dos papéis.

Henry, que ocupa uma posição dupla de narrador e protagonista, frequentemente manifesta a dupla consciência que Du Bois descreve.

${ }^{13}$ Para uma longa análise do imigrante como espião e as maneiras pelas quais Native speaker subverte as convenções típicas do romance de espionagem, consulte Tina Chen (2002). 
Logo no início do romance, durante uma das primeiras conversas de Henry com Lelia antes do casamento, a questão sobre o seu sotaque surge e ele afirma: "Pessoas como eu estão sempre pensando no fato de ainda terem um sotaque" (Lee, 1995, p. 12). Como um observador da cultura, Henry está perfeitamente ciente das maneiras pelas quais a linguagem revela e trai a identidade, especialmente a sua própria. Em resposta à sua confissão, Lelia diz: "Seu rosto faz parte da equação, mas não do jeito que está pensando. Você é como alguém que está se ouvindo. Você dá atenção a aquilo que faz. Se eu tivesse de adivinhar, diria que você não é um falante nativo" (Lee, 1995, p. 12). Lelia percebe a dupla consciência de Henry, a hiperconsciência de sua identidade hifenizada, uma consciência que contribui para a sua alienação. Entretanto, Lelia também serve como "o símbolo do romance de brancura normativa" (Corley, 2006, p. 70). Ela própria afirma nesta mesma passagem: "Infelizmente, sou a porta-estandarte" (Lee, 1995, p. 12). A confissão de Lelia constitui um dos desafios enfrentados pelos asiático-americanos. Lelia representa um padrão, um modelo normativo da identidade americana em que a brancura é definida tanto pela linguagem e sotaque quanto pela raça. ${ }^{14}$ Sobre esse aspecto Liam Corley (2006, p. 72) observa: "Ser coreano e ao mesmo tempo um falante nativo implica uma contradição que exige a desconstrução de falantes brancos de inglês como nativos".

A tensão que Henry sente entre o desejo de preservar a sua herança étnica ou assimilar totalmente a cultura americana é simbolicamente representada pelos dois homens mais velhos que ele observa de perto: seu pai e John Kwang, o coreano-americano candidato a prefeito. Ao contrário do desejo apreensivo de Henry de superar sua condição de hifenizado, o pai de Henry se agarra a sua identidade coreana. Por exemplo: o pai se autoidentifica como coreano-americano e "gostava de demorar-se no hífen" (Lee, 1995, p. 144). O pai de Henry, da mesma forma, entende o poder da linguagem e abraça seu papel de imigrante com sotaque que não abre mão da identidade coreana. Henry nota algo mais em relação a seu pai: "Às vezes, quando queria esconder ou não mentir abertamente, escolhia falar em inglês" (Lee, 1995, p. 63). Semelhante à própria capacidade de Henry de entrar e sair dos papéis,

\footnotetext{
${ }^{14}$ Tim Engles, de fato, criticou o romance pela maneira que inconscientemente continua a defender a classe média americana 'brancura dóxica', manifestada no "comportamento e costumes americanos" (1997, p. 28).
} 
o pai usa o inglês para esconder, ocultar e de certa forma preservar seu senso de identidade, sua alteridade. Por outro lado, John Kwang, o político que Henry espiona ao longo do romance, resiste ativamente à maneira como a mídia constantemente tenta marginalizá-lo ou reduzilo a um político "étnico" de cor: "Não importa o que eu digo, fazem disso uma questão de raça. O homem amarelo se pronuncia" (Lee, 1995, p. 274). Tim Engles eloquentemente captura a tensão entre esses dois homens quando afirma: "Ao delinear sensitivamente os casos emblemáticos de atração e repulsão, Henry sente cada uma dessas figuras em sua vida. O romance de Lee consegue expor uma tensão na América (em termos bakhtinianos) entre o sentimento centrípeto e assimilacionista da cultura dominante e sua tendência estratificada e centrífuga de manter as pessoas de cor a distância" (1997, p. 29). Henry, assim, oscila entre esses dois impulsos.

Nova York surge no romance como a cidade para imigrantes por excelência, incorporando as tensões manifestadas na vida de Henry. A cidade oferece esperança ao mesmo tempo para aqueles que desejam a assimilação e para aqueles que desejam manter a sua alteridade étnica. Significativamente, Lee mostra John Kwang como um vereador do Queens, bairro muito conhecido como a comunidade mais diversificada nos Estados Unidos, com mais de 160 idiomas diferentes: "Havia todos os tipos, entrando e saindo, trabalhando e negociando, esses pelotões de coreanos, indianos, vietnamitas, haitianos, colombianos, nigerianos, esses quaisquer pardos e amarelos, sejam quem forem, um sem-número de ninguéns" (Lee, 1995, p. 83). Liam Corley observa:

Lar da Estátua da Liberdade, Ellis Island, Edifício Empire State, Wall Street, Broadway, Madison Avenue e as Nações Unidas, Nova York é um símbolo importante da construção imaginada da nação em termos domésticos e transnacionais. Cada um desses ícones nacionais e internacionais mantém um vida dupla como signos dos laços materiais e políticos entre Nova York e a comunidade global (Corley, 2006, p. 62).

Nova York assim representa um símbolo poderoso de dupla camada da identidade da nação americana, bem como símbolo da conectividade global e multicultural, e essa função simbólica paralela realça a própria consciência dupla de Henry Park.

A dupla identidade de Henry transmite metaforicamente o desafio que uma sociedade multicultural enfrenta. A certa altura do romance 
Henry confessa: "Foi a proximidade, e não o tato, que sempre me compeliu. Conheço apenas a proximidade" (Lee, 1995, p. 130). A crítica principal do belo mosaico e da salada mista como metáforas para a identidade americana é que a imagem enfatiza a proximidade cultural, em vez de intercâmbio cultural e hibridismo. Modelos de hibridismo cultural arriscam a perda de modos normativos de comportamento cultural em favor das evoluções culturais inesperadas. A metáfora do mosaico preserva ambas as culturas dominantes e marginalizadas, acentuando a diferença cultural. Como exemplo de implicações redutoras para a metáfora do mosaico, Henry acredita no início do romance que a solução para a sua crise de identidade é apenas uma questão de identificar o lugar ao qual realmente pertence, e ele inicialmente acredita ser a sua posição como espião cultural: "Fui alguém que podia ficar no seu lugar e dar meio passo para fora quando queria. [...] Eu finalmente encontrara meu verdadeiro lugar na cultura" (Lee, 1995, p. 127). Aqui Henry reconhece que esse é o papel que a sociedade dos Estados Unidos lhe oferece mais facilmente: a de alguém que mora na periferia, que pode sair de vez em quando e se retirar quando necessário.

Ao longo do romance, porém, Henry percebe que essa posição restritiva e marginalizada em última análise permanece insatisfatória. Henry afirma: "O contador, eu sei, pode ficar nas sombras apenas até certo ponto. Queremos que ele saia, dê um passo em direção à luz e se revele. Essa é a forma da nossa época" (Lee, 1995, p. 204). Henry anseia por deixar cair a máscara. Ele deseja atuar na sociedade não como um espião ou impostor, mas de forma autêntica. No final do romance Henry descobre que não existe solução fácil para sua crise de identidade. Embora permaneça totalmente consciente das complexidades de seu própria performance (Chen, 2002, p. 653), ele não consegue compreender a diferença entre o seu desempenho dúplice como espião e agente cultural e seu desempenho como ele mesmo. De modo significativo, Henry desiste de sua carreira na espionagem para trabalhar com sua esposa, Lelia, uma professora de inglês para crianças. Tais atos simbólicos demonstram o desejo de Henry de parar de se passar por outros e "dar um passo em direção à luz e se revelar" (Lee, 1995, p. 204).

$\mathrm{Na}$ cena final, Lelia e Henry leem historinhas e fazem jogos de palavras com as crianças, que são na sua maioria falantes de língua estrangeira. Nesse momento, o romance oferece talvez a resposta mais 
provocativa ao forte desejo por diferença que sustenta a cultura normativa dos Estados Unidos. Lelia lê uma história, sabendo que algumas crianças podem não entender: "Não importa o que entendem. Ela quer que saibam que não há nada a temer, ela quer se oferecer uma mulher branca e pálida brincando com a linguagem para demonstrar que não tem problema bagunçar tudo" (Lee, 1995, p. 349). Aqui Lelia e Henry juntos surpreendem as crianças: Lelia com seu uso visivelmente raro do inglês sendo uma mulher branca, e Henry com sua habilidade notavelmente correta de falar inglês como um asiático-americano. Alguns críticos acharam o desfecho do romance insatisfatório porque Henry parece em última análise incapaz de resolver o dilema de sua identidade (Chen, 2002, p. 660). No entanto, a cena final do romance sugere pelo menos uma avenida positiva para o futuro da nação. Ao abordar o estigma do uso da linguagem e incentivando as crianças imigrantes a brincar com o idioma e "bagunçar tudo", o romance desafia a maneira como a brancura normativa está vinculada a uma forma particular de inglês ao promover novas formas híbridas de expressão.

\section{O sol se põe em São Paulo e o multiculturalismo brasileiro}

De forma parecida com Native speaker de Lee, O sol se põe em São Paulo é um romance centrado na vida urbana imaginária de São Paulo, a megalópole do Brasil, que, assim como Nova York, serve como um poderoso símbolo da identidade nacional brasileira. Ao contrário do Rio de Janeiro, outro grande símbolo de cidade do Brasil, São Paulo adquiriu o seu capital simbólico, principalmente no início do século XX, quando a economia brasileira se industrializou. Na verdade, poucas cidades no Brasil incorporam com mais força a modernidade de São Paulo, que tem sido o lar não apenas de escritores modernistas, artistas e intelectuais mas também de milhões de migrantes e imigrantes que vieram para a cidade no século $X X$, fugindo da opressão, da miséria e da perseguição em busca de paz, liberdade, bem-estar e riqueza. Ao longo do século $X X$, um grande número de imigrantes veio para a cidade vindo de Portugal, Itália, Espanha, Alemanha, Japão, Oriente Médio e Europa Oriental, fazendo de São Paulo a maior cidade do 
Brasil, bem como a mais diversificada culturalmente, com uma população que já totaliza mais de vinte milhões de pessoas. ${ }^{15}$

Apesar da sua importância econômica e cultural, São Paulo serve como um símbolo inquieto da identidade nacional. Celebrada como a capital financeira do Brasil, o centro da sexta maior economia do mundo, São Paulo representa o maior sucesso econômico do Brasil e também continua a ser um influente centro da cultura e da criatividade intelectual. No entanto, também é o lar de milhões de moradores que vivem abaixo da linha de pobreza, e os críticos condenam a cidade por seus altos níveis de pobreza e criminalidade. Dessa forma, São Paulo representa tipicamente o apelido muitas vezes repetido no Brasil, de ser uma terra de contrastes. Assim como o narrador de $O$ sol se põe em São Paulo afirma no início do texto, São Paulo é "uma cidade sitiada pela miséria e pelo crime, dos quais esse mesmo poder se alimenta embora tente em vão excluí-los" (Carvalho, 2007, p. 14). Extrema riqueza e extrema pobreza, fundamentalmente, definem e dividem a cidade entre aqueles com meios e que têm acesso ao capital financeiro, educacional e social, e aqueles que não têm.

Os problemas do Brasil decorrentes da desigualdade econômica e privação social, que são claramente configurados segundo a raça e a etnia, de forma clara manifestam-se em São Paulo, onde os excluídos são referidos como "periferia". O narrador de O sol se põe em São Paulo ironicamente observa: "São Paulo não se enxerga - ou não chamaria periferia de periferia. Não é só eufemismo. Chamam-se excluídos aos $80 \%$ da população" (Carvalho, 2007, p. 14). Aqui o narrador sugere que o tamanho de São Paulo e sua escala não apenas amplificam os problemas sociais da cidade mas também contribuem para uma perspectiva distorcida da sociedade. Percepções distorcidas abundam em São Paulo. Na verdade, como uma das maiores áreas metropolitanas do mundo, com seu sistema de transporte complexo e muitas vezes frustrante e o esmagamento da população, São Paulo pode facilmente oprimir e desorientar visitantes e residentes.

O sol se põe em São Paulo (2007), o oitavo romance publicado por Bernardo Carvalho, um dos romancistas contemporâneos mais célebres do Brasil, aparentemente tem pouco a ver com a São Paulo

\footnotetext{
${ }^{15}$ Para um excelente estudo de padrões de imigração para o Brasil, ver a coleção de ensaios organizada por Boris Fausto (1999).
} 
contemporânea e seus desafios urbanos. A história começa e termina na cidade, mas a maior parte do romance centra-se em pessoas e eventos no Japão sessenta anos antes. A história segue as complicações de um narrador sem nome, neto de imigrantes japoneses, que é contratado por uma mulher idosa japonesa chamada Setsuko para escrever a sua história, uma história de amor sem final feliz que começa no Japão e termina no Brasil. Com uma narrativa dentro de uma narrativa, o romance está repleto de episódios labirínticos, narrativas com flashbacks, identidades trocadas e escondidas, e revelações inesperadas que levam o leitor do Brasil ao Japão, do presente ao passado e vice-versa.

Entretanto, apesar de seu foco no Japão, o romance é mais um romance sobre o Brasil e a contemporânea São Paulo, ainda que mais no tema do que no conteúdo. Ambos os narradores - o narrador sem nome da história e Setsuko - demonstram inquietações profundas decorrentes da necessidade de encontrar a verdade para conhecer e ser conhecido em uma cidade condicionada pela publicidade, desorientação, dissimulação, ilusão e desorientação. O narrador, por exemplo, refere-se a São Paulo como uma cidade de "publicitários" de uma forma que se assemelha a campanha constante de John Kwang e autopropaganda em Native speaker. A desconexão entre aparências e realidade faz com que tanto o narrador quanto Setsuko se sintam alienados, marginalizados e excluídos da sociedade, e ambos expressam desejos de autenticidade mesmo quando demonstram consciência dos vários papéis que foram chamados a executar. Dessa forma, o romance estende a noção de periferia além da dialética branco/negro e rico/pobre para resolver os problemas sociais e políticos de representação, visibilidade e invisibilidade, inclusão e reconhecimento para a população minoritária de nipo-brasileiros.

Enquanto São Paulo serve como uma moldura e pano de fundo para a história interior que acontece no Japão, no decorrer do romance, a experiência externa do narrador, que vive na megalópole brasileira, cria forma ao desejo mais existencial do romance: o desejo de autoconhecimento, para ver a si mesmo, para encontrar um rumo em uma cidade marcada pela desorientação. Douglas Tallack (2012) argumenta que a estrutura que define a arquitetura metropolitana, o arranha-céu, tem sido parte integrante da estética modernista por causa da maneira pela qual os arranha-céus mudaram e desafiaram a forma como as pessoas veem a cidade. Tallack propõe que, em contraste com uma estética do ponto de vista mais elevado, a literatura urbana é mais 
familiarizada com perspectivas pé no chão. Considerando que as perspectivas mais elevadas trazem distância em larga escala, totalizando pontos de vista que se prestam a visões unificadas da nação, literatura de baixo crescimento que se concentra nos espaços ao nível do solo do multiculturalismo, o trilho, encontros e intercâmbios culturais. Ambas as perspectivas são importantes para a identidade nacional. Embora situado em uma cidade de arranha-céus, $O$ sol se põe em São Paulo adota uma forma de baixo crescimento, uma estética ao nível plano. Ao pisar no solo em São Paulo, a perspectiva é tanto perder ou ganhar. Em uma cidade de arranha-céus, as baixas perspectivas não conseguem compreender visões abrangentes da cidade e da nação. Perspectivas de baixo crescimento lutam para captar imagens coesas e unificadas do todo. No entanto, a estética de uma narrativa com postura inferior evita o que Nelson Vieira chama de "impulso cultural rumo à homogeneidade" (1995, p. 12) em favor da fragmentação, da ruptura, da alteridade e da diferença. Embora a estética inferior talvez não seja capaz de ver o todo, ela está mais apta a ver as partes para identificar os elementos culturais únicos e particulares frequentemente omitidos no discurso totalizante da identidade nacional.

O sol se põe em São Paulo tacitamente reconhece o desejo nacionalista de homogeneidade cultural, procurando desvendar a complexa história de um dos grupos étnicos marginalizados no Brasil. Essa história é simbolizada pelo bairro paulistano da Liberdade, a maior comunidade de japoneses fora do Japão. Com a sua bem reconhecível entrada, decorações e os vários sinais em japonês, a Liberdade possui uma arquitetura e marcos simbólicos da alteridade. Ainda assim, o desejo arquitetônico dominante do bairro - parecer estar em um lugar diferente do qual realmente se encontra - na verdade, corresponde bem ao resto da cidade. O narrador, por exemplo, afirma: “A Liberdade é um desses bairros de São Paulo que [...] ressalta no mau gosto da sua rala fantasia arquitetônica o que a cidade tem de mais pobre e de paradoxalmente mais autêntico: a vontade de passar pelo que não é" (Carvalho, 2007, p. 14). Embora as fachadas do bairro pareçam expressar autêntica diferença cultural, o narrador questiona a autenticidade do que elas simbolizam. O bairro, argumenta ele, não pode ser entendido quando removido de seu contexto na maior megalópole, uma cidade de ilusões. Ele afirma ainda: 
Na liberdade, nem mesmo um bêbado, ao sair trôpego de um restaurante, acreditando que é escritor, pode achar que está numa megalópole violenta do Terceiro Mundo. E, no entanto, é disso que as ruas de São Paulo tentam convencer quem passa por elas: que está em outro lugar, num esforço inútil de aliviar a tensão e o incômodo de estar aqui, o mal-estar de viver no presente e de ser o que é (2007, p. 15).

Em vez de proporcionar uma forte sensação de estabilidade e de identidade ao narrador, que, por sua vez, reconhece sua herança japonesa sem se sentir japonês, o bairro da Liberdade com suas fachadas, ilusões e caricaturas aumenta o sentimento de desconforto e deslocamento. Nelson Vieira escreve: “Quando consideramos o espírito nacionalista de síntese e integração cultivado no Brasil durante quase dois séculos, o conceito de alteridade surge como um modo bastante útil para examinar a ideologia, literatura e civilização nacional brasileira vis-à-vis indivíduos ou grupos que não se encaixam culturalmente no padrão oficial nacional" (Vieira, 1995, p. 6). Nesse sentido, da mesma forma que a Liberdade desafia em termos arquitetônicos e estéticos o padrão nacional da identidade brasileira, o narrador de $O$ sol se põe em São Paulo não pode também estar de acordo com o "padrão nacional oficial". Sua consciência do fato e da desorientação que se segue simboliza a alienação sentida por todas as etnias e grupos sociais que não têm representação e nem são vistos como parte da imagem nacional do Brasil.

O sol se põe em São Paulo apresenta São Paulo como uma cidade permeada de mal-estar e inquietação causados pela marginalização sistemática, desorientação e insegurança. Esse sentimento se manifesta de forma marcante na experiência do narrador, que habita em sua própria posição peculiar de instabilidade. Para usar os termos de Vieira, o narrador não é nem parte nem estranho, isto é, ocupa uma posição cultural instável entre as duas culturas que oscila entre a alienação que ele sente da sociedade brasileira por causa de sua herança japonesa e a falta de conexão que sente em relação a sua própria herança. Como Stefania Chiarelli afirma: "O personagem se move entre distintas referências e temporalidades, em narrativa que problematiza o hibridismo como uma das marcas históricas das culturas latinoamericanas [...]. O personagem brasileiro traz resquícios da cultura japonesa, resíduos de uma tradição com a qual não consegue lidar" (2007, p. 74). Pelo menos inicialmente, o romance reduz hibridismo a 
uma qualidade fundamental da identidade precisamente ao demonstrar a incapacidade desse narrador de ser híbrido, conciliar ou harmonizar as peças componentes de sua própria cultural. Em outras palavras, o narrador habita em um mundo social que não privilegia o hibridismo, ou pelo menos o particular coquetel de sua composição cultural. Essa posição instável talvez possa igualmente explicar a razão pela qual ele continua sem nome no texto, como Sandra Sousa sugere: "Como homem entre dois mundos, o da cultura brasileira e o da cultura japonesa, não se sentindo pertencente a nenhum e tentando preencher o seu 'eu' frustrado através da vida de outros escritores, a ausência de nome poderá significar a impossibilidade de o nome definir a identidade desta personagem" (2010, p. 190). O anonimato do narrador metaforicamente simboliza sua posição cultural ambivalente - ele representa uma figura cujo local ainda não foi definido/nomeado. Chiarelli observa: "Persiste a contradição entre o desejo de pertencer a um conjunto de valores e o de rechaçar a identidade japonesa" (2007, p. 74).

Ao longo dos primeiros capítulos do romance, o narrador expressa repetidas vezes seu não pertencimento à sociedade brasileira. Em uma tentativa de assimilar-se completamente e ser totalmente brasileiro, ele afirma: "Durante muito tempo, eu tentei fugir como o diabo da cruz de tudo o que fosse japonês" (Carvalho, 2007, p. 28). No entanto, ele reconhece que é impossível ignorar a origem cultural de sua família: "Podíamos ter perdido os costumes e a língua, mas as origens nos chamavam de volta" (Carvalho, 2007, p. 29). Ele não pode negar a força cultural das origens de sua família. O que frustra o narrador é como voltar às suas origens. O que significa voltar? Ele reconhece que não pode retornar como um simples operário para o Japão, algo que acreditava que seria: "perpetuar o fracasso e o erro" (Carvalho, 2007, p. 20). O que o personagem deseja é na verdade um retorno híbrido, uma reconciliação simbólica entre dois mundos. Ele entende que, assim como não pode virar as costas para as origens de sua família, não pode ignorar a sua própria posição social/cultural: sua terra natal e língua materna portuguesa, embora não se sinta totalmente brasileiro. Talvez seja por essa razão que ele se volta para a escrita, o espaço de significação simbólica. O narrador exige uma mediação simbólica: “Eu tinha esgotado todas as chances de fazer parte deste mundo, de me sentir integrado a ele, e que não bastava falar português, ter nascido e viver no Brasil, era preciso escrever também" (Carvalho, 2007, p. 19). Essa 
ansiedade impulsiona a necessidade de escrever tanto do narrador quanto de Setsuko - a não apenas falar, mas para escrever a história. Existe uma ansiedade, uma pressão, uma "pressa", uma necessidade não apenas de falar, mas de escrever e simbolicamente unir as duas metades de sua identidade, ou como Dom Casmurro diria: "atar as duas pontas da vida" (Machado de Assis, 1959, p. 50).

Para Setsuko e o narrador, uma vez que em conjunto começam a escrever a história, o processo de escrita não só lhes permite iniciar o processo de conciliar mundos divergentes, mas permite-lhes, simultaneamente, ver através das ilusões, do desmascaramento, da verdade revelada. Escrever ainda lhes permite compreender as várias funções que a sociedade lhes ofereceu - papéis que eles escolheram e papéis que lhes foram impostos. O narrador descobre, por exemplo, que não pode escrever a história de Setsuko passivamente, pois no ato da escrita, ele se torna parte da história. Assim como Henry Park descobre que a linguagem confere várias formas de identidade, o narrador de $O$ sol se põe em São Paulo acha que escrever também o investe com identidade, implicando-o na história, bem como dando-lhe um papel a desempenhar. Após descobrir seu novo papel no drama, o narrador afirma: “Agora, teria um papel ativo na traição. Passava da escuta ao ato" (Carvalho, 2007, p. 55).

Como Henry Park em Native speaker, o narrador de $O$ sol se põe em São Paulo tem de aprender a navegar por uma série de papéis que ele mesmo escolheu ou que foram herdados. O narrador é um cidadão brasileiro, falante nativo de português com um rosto oriental e uma herança imigrante; um escritor uma vez fracassado, mas também o autor da história de Setsuko e, finalmente, um personagem da história. Parte da viagem de autodescoberta do narrador é aprender, como um espião ou detetive, para juntar os elementos de sua vida e história de forma coesa e compreensível. Por volta da metade do texto, quando ele tenta dar sentido a história de Setsuko, o narrador afirma com certa frustração: "Eu era o mais estúpido dos homens. Não conseguia juntar as peças, embora tudo estivesse diante de mim" (Carvalho, 2007, p. 99). Essa exclamação vem à medida que o narrador começa a perceber a verdadeira identidade de Setsuko e entender o seu próprio papel na história. Posteriormente o narrador alcança um sentido mais iluminado de si: "No fundo, todas as máscaras confirmam quem você é. Pois é você que as usa" (Carvalho, 2007, p. 156). Essa noção performativa sugere a 
forma positiva pela qual o hibridismo, juntamente com uma identidade composta, pode funcionar no Brasil.

No final do texto, as tensões que narrador sentia inicialmente a respeito das contradições entre sua ascendência japonesa e a sua identidade brasileira não foram resolvidas, mas aceitas. Através do processo de escrever a história de Setsuko, o narrador descobre uma verdade importante sobre identidade, como ele diz: "não sei o que é memoria e o que é imaginação" (Carvalho, 2007, p. 137). A identidade resulta de ambas: memória e imaginação. É ao mesmo tempo a herança e criação: passado e futuro.

O sol se põe em São Paulo, em última análise, apresenta um modelo para a identidade brasileira que evita tropos nacionais facilmente resolvíveis e estáveis. Nesse romance, como é característica de grande parte de sua ficção, Carvalho abraça a instabilidade como uma técnica narrativa: ele está constantemente puxando o tapete do leitor. No entanto, essa técnica narrativa é mais do que um mero artifício estético. Ao desafiar os clichês estáveis do país, $O$ sol se põe em São Paulo questiona não somente o que significa ser brasileiro, mas também como a identidade brasileira se expressa. Klinger observa que a ficção de Carvalho frequentemente apresenta: "uma trama labiríntica na qual os personagens vivem sob a ameaça da perda da identidade" (2007, p. 157). O narrador resume: “Uma história de párias, como eu e os meus, gente que não pode pertencer ao lugar onde está, onde quer que esteja, e sonha com outro lugar, que só pode existir na imaginação em nome da qual ela me contou uma história que pergunta sem parar a quem a ouve como é possível ser outra coisa além de si mesmo" (Carvalho, 2007, p. 163-164). No final, assim como a história pede ao narrador e, por extensão, à sociedade brasileira para abraçar a alteridade do nipobrasileiro como uma forma de identidade brasileira, a história simultaneamente clama que o leitor abrace a sua própria marginalidade. É uma chamada ambiciosa para uma noção radicalmente inclusiva da identidade nacional.

\section{Conclusões: a evolução de nossas identidades nacionais compostas}

Tanto nos Estados Unidos quanto no Brasil, as inquietações a respeito dos imigrantes (o anseio por assimilação e autenticidade) são 
frequentemente manifestadas pelo grau em que grupos de imigrantes são capazes de realizar as funções atribuídas a eles pela sociedade anfitriã. Native speaker e $\mathrm{O}$ sol se põe em São Paulo igualmente dependem de noções de desempenho racial e étnica, mesmo assim abordam a questão de direções opostas. Cada romance responde a um modelo diferente de configuração racial: uma definida por uma linha de cor e a outra definida pela mistura racial e hibridismo. Há vantagens e desvantagens para ambos os modelos. Os Estados Unidos favorecem a redefinição de diferença, que inicialmente assumiu a forma de racismo e preconceito explícito e agora existe através de um modo politicamente correto e por vezes presunçoso que se manifesta através da hifenização da identidade às custas de um modelo nacional inclusivo. O Brasil, por outro lado favoreceu uma identidade nacional multirracial/híbrida forte (embora o branco seja o privilegiado), que veio à custa do reconhecimento da diferença. Portanto, Native speaker luta contra as noções politicamente corretas de segregação nas quais o narrador, Henry Park, procura formas de ir além do hífen para um sentimento de americanidade que não seja circunscrito pela linha de cor. Por outro lado, $O$ sol se põe em São Paulo segue em direção oposta, o narrador está em crise justamente por causa de sua identidade como sansei, ou seja, como um nipo-brasileiro que ainda não foi totalmente reconhecido pela nação. O romance luta contra o impulso nacional a favor de um sentido unido e estável de identidade, indo em direção à instabilidade. Enquanto existem certamente algumas vertentes da literatura brasileira que buscam um consenso, que visam uma resolução, as frases finais de $O$ sol se põe em São Paulo são claramente dirigidas não apenas para um outro sansei, mas para nós, leitores forçados a reconhecer essa história aparentemente estranha e exótica como se fosse a nossa própria história. O romance torna-se assim uma forma de revelar o hífen oculto da identidade nipo-brasileira, mesmo quando Native speaker tem a intenção de apagá-lo.

O crítico norte-americano Jules Chametzky tem enfatizado repetidamente o fato de que a "cultura" não é um termo que está pronto para ser aceito ou rejeitado. Ele afirma: "Hoje, como no passado, há apenas desavença, luta, o desfazer e o fazer, descobrimento e criação, perdas e ganhos" (1989, p. 13). Em resposta a tais negociações, tanto Native speaker quanto $O$ sol se põe em São Paulo apresentam modelos complementares para a identidade nacional que vê a diferença como uma fonte potencialmente positiva. Nos confrontos finais de Native speaker, o 
político aspirante John Kwang lamenta: “Este país tem uma diferença que aflige mais do que fortalece e enriquece. Você pode ver o que pode acontecer a partir disso, como o público pode começar a ver qualquer ato fora do normal da cultura como algo ameaçador ou perigoso. Algo está se fechando, Henry, lenta mas gradualmente, um restringimento de quem pode legitimamente viver aqui e ser considerado" (Lee, 1995, p. 274). Se a avaliação do Kwang a respeito da sociedade contemporânea está correta, Native speaker e $O$ sol se põe em São Paulo, ambos, apresentam uma voz forte contra uma "diferença que aflige" (Lee, 1995, p. 274). Em confissão recente sobre o seu romance, Bernardo Carvalho afirma: "É um livro sobre o poder da literatura [...] assim como sobre o forte potencial criativo de uma singularidade radical e subjetiva" (Carvalho, 2010, p. 4). Henry Park, o protagonista de Native speaker, reconhece do mesmo modo o poder singular da narração: "A verdade, por fim, é quem pode contá-la" (Lee, 1995, p. 7). E, ao contar as suas histórias, os narradores de ambos os romances revelam o poder libertador e enriquecedor das identidades mistas do indivíduo e da nação.

\section{Referências}

AZEVEDO, Celia Maria Marinho de (2003). Abolicionismo: Estados Unidos e Brasil, uma história comparada. São Paulo: Annablume.

BAILEY, Ferreira-Pinto; ZILBERMAN, Regina (2010). Brasil, Brasis, ou: a hora e a vez das minorias étnicas. Revista Iberoamericana, v. 76, n. 230, p. 11-21.

CARVALHO, Bernardo (2010). Fiction as exception. Luso-Brazilian Review, v. 47, n. 1, p. 1-10.

CARVALHO, Bernardo (2007). O sol se põe em São Paulo. São Paulo: Companhia das Letras.

CHAMETZKY, Jules (1989). Beyond melting pots, cultural pluralism, ethnicity: or, déjà vu all over again. Melus: journal of the society for the study of the multiethnic literature of the United States, v. 16, n. 4, p. 3-17.

CHEN, Tina (2002). Impersonation and other disappearing acts in native speaker. Modern Fiction Studies, v. 48, n. 3, p. 637-667.

CHIARELLI, Stefania (2007). As coisas fora do lugar: modos de ver em Bernardo Carvalho. Estudos de Literatura Brasileira Contemporânea, n. 30, p. 71-78. 
CORLEY, Liam (2006). Just another ethnic pol: literary citizenship in Chang-rae Lee's Native speaker. In: LIMA, Shirley Geok-lin et al. (Org.). Transnational asian american literature: sites and transits. Philadelphia: Temple University Press.

COOPER, Rand Richards (1995). Excessive identities. New York Times, 9 abr.

DANIEL, G. Reginald (2006). Race and multiraciality in Brazil and the United States: converging paths? University Park: The Pennsylvania State University Press.

DU BOIS, W. E. B. (1903). The souls of black folk: essays and sketches. Chicago: A. C. McClurg \& Co.

ELLISON, Ralph (1952). Invisible man. New York: Vintage Books.

ENGLES, Tim (1997). Visions of me in the whitest raw light: assimilation and doxic whiteness in Chang-rae Lee's Native speaker. Hitting Critical Mass: a journal of asian american cultural studies, v. 4, n. 2, p. 27-48.

FABRIS, Mariarosaria (2007). A questão realista no cinema brasileiro: aportes neorrealistas. Alceu, v. 8, n. 15, p. 82-94.

FAUSTO, Boris (Ed.) (1999). Fazer a América. São Paulo: Editora USP.

FONG, Mary; CHUANG, Rueyling (Ed.) (2004). Communicating ethnic and cultural identity. Oxford: Rowman \& Littlefield Publishers.

GLAZER, Nathan; MOYNIHAN, Daniel (1963). Beyond the melting pot: the negroes, puerto ricans, jews, italians and irish of New York city. Cambridge: MIT Press.

GLEASON, Philip (1964). The melting pot: symbol of fusion or confusion? American Quarterly, v. 16, n. 1, p. 22-46.

GORDON, Milton (1964). Assimilation in american life: the role of race, religion and national origins. Oxford: Oxford University Press.

HAMILTON, Charles V. et al. (2001). Beyond racism: race and inequality in Brazil, South Africa, and the United States. London: Lynne Rienner.

HANNERZ, Ulf (1992). Cultural complexity: studies in the social organization of meaning. New York: Columbia University Press.

KELLER, Mary; FONTENOT, Chester J. (Org.) (2007). Re-cognizing W.E.B. DuBois in the twenty-first century: essays on W. E. B. Du Bois. Macon: Mercer University Press.

KLINGER, Diana Irene (2007). Escritas de si, escritas do outro: o retorno do autor e a virada etnográfica. Rio de Janeiro: 7Letras. 
LEE, Chang-rae (2003). Mute in an english-only world. In: SHREVE, Susan (Org.). Dream me home safely: writers on growing up in America. New York: Mariner Books.

LEE, Chang-rae (1995). Native speaker. New York: Riverhead Books.

LESSA, Ricardo (2008). Brasil e Estados Unidos: o que fez a diferença. Rio de Janeiro: Civilização Brasileira.

LESSER, Jeffrey (1999). Negotiating national identity: immigrants, minorities, and the struggle for ethnicity in Brazil. Durham: Duke University Press.

MACHADO DE ASSIS, José Maria (1959). Dom Casmurro. Obras completas. Rio de Janeiro: Aguilar.

MARTINS, Pablo (2002). O anonimato em primeiro plano. São Paulo: Aruanda/ECA-USP, dez. Disponível em: <http://goo.gl/kREYwJ>. Acesso em: 3 mar. 2012.

MARX, Anthony W. (1998). Making race and nation: a comparison of the United States, South Africa, and Brazil. Cambridge: Cambridge University Press.

PERSONS, George (Org.) (2003). Race and democracy in the Americas. New Brunswick: Transaction Publishers.

PETERSON, Charles F. (2007). DuBois, Fanon, Cabral: the margins of elite anticolonial leadership. Lanham: Lexington.

SANTIAGO, Silviano (2001). The space in-between: essays on latin american culture. Durham: Duke University Press.

SEIGEL, Michol (2009). Uneven encounters: making race and nation in Brazil and the United States. Durham: Duke University Press.

SKIDMORE, Thomas E. (1993 [1974]). Black into white: race and nationality in brazilian thought. Durham: Duke University Press.

SOUSA, Sandra (2010). Conheces o nome que te deram, não conheces o nome que tens: a questão identitária do nome próprio e a experiência nipo-brasileira em $O$ sol se põe em São Paulo de Bernardo Carvalho. Revista Iberoamericana, v. 76, n. 230, p. 187-199. (Dossiê Brasil, Brasis, ou: a hora e a vez das minorias étnicas.)

SOUZA, Jessé (1997). Multiculturalismo e racismo: uma comparação BrasilEstados Unidos. São Paulo: Paralelo 15.

STAM, Robert (1997). Tropical multiculturalism: a comparative history of race in Brazilian cinema and culture. Durham: Duke University Press.

TALLACK, Douglas (2012). Tall stories: New York skyscrapers in art and literature. In: SPATIAL PERSPECTIVES: Literature and Architecture, 1850- 
Present. Oxford, University of Oxford, 22 jun. (Comunicação em evento.) Disponível em: <http://goo.gl/IxCWDT>. Acesso em: 30 mai. 2014.

TELLES, Edward E. (2004). Race in another America: the significance of skin color in Brazil. Princeton, NJ: Princeton University Press.

TINNEMEYER, Andrea (2006). Identity politics of the captivity narrative after 1848. Lincoln: University of Nebraska Press.

VIEIRA, Nelson H. (1995). Jewish voices in brazilian literature: a prophetic discourse of alterity. Gainseville, FL: University Press of Florida.

ZANGWILL, Israel (1909). The melting pot. New York: Macmillan.

Recebido em junho de 2014.

Aprovado em outubro de 2014.

\section{resumo/abstract}

\section{Reorientando a identidade nacional em Native speaker, de Chang-rae Lee, e $O$ sol se põe em São Paulo, de Bernardo Carvalho}

Rex P. Nielson

Uma leitura comparativa entre os romances Native speaker (1995), do escritor norte-americano Chang-rae Lee, e O sol se põe em São Paulo (2007), de Bernardo Carvalho, permite uma reavaliação da construção das identidades minoritárias presentes nas duas megalópoles americanas de Nova York e São Paulo. Os enredos dos dois romances são marcados por uma crise de identidade vivida por um homem, descendente de imigrantes asiáticos (da Coreia num caso e do Japão no outro), que procura negociar sua identidade americana (falando em termos hemisféricos) em termos da origem e língua de sua família. Contudo, apesar das ansiedades parecidas sobre a assimilação presentes nos dois romances, ambos revelam diferenças significativas em relação às formas como os Estados Unidos e o Brasil responderam às diferenças culturais ao mesmo tempo que desafiam os mitos nacionais de inclusão e pertencer.

Palavras-chave: diferença cultural, raça, identidade nacional, Bernardo Carvalho, Chang-rae Lee. 


\section{Re-orienting national identity in Native Speaker, by Chang-rae Lee, e 0 sol se põe em São Paulo, by Bernardo Carvalho}

Rex P. Nielson

A comparative reading of the novels Native speaker (1995), by the North American writer Chang-rae Lee, and $O$ sol se põe em São Paulo (2007), by Bernardo Carvalho, allows for a reevaluation of how minority identities have been constructed in the two American megalopolises New York and São Paulo. The plotlines of both novels hinge on the identity crisis of a second-generation Asian immigrant (from Korea in one case and Japan in the other) who is seeking to negotiate his American identity (speaking in hemispheric terms) in terms of his family's origin and language. However, despite the similar anxieties over assimilation present in both novels, they both reveal significant differences regarding the ways in which the United States and Brazil have responded to cultural difference even as they challenge national myths of inclusion and belonging.

Keywords: cultural difference, race, national identity, Bernardo Carvalho, Chang-rae Lee. 